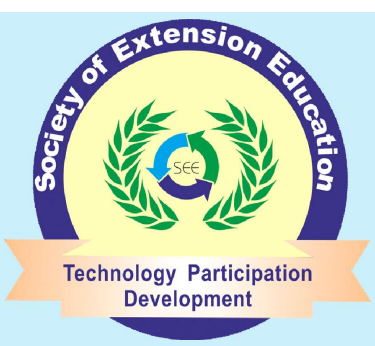

Research Article

\section{Indian Research Journal of Extension Education}

ISSN: 0972-2181 (Print), 0976-1071 (Online)

NAAS Rating : 5.22

Journal homepage: seea.org.in

https://doi.org/10.54986/irjee/2022/jan_mar/32-37

\title{
Factors Affecting Machinations at Dairy Farms : An Appraisal from Economic Perspective
}

\author{
H.R. Meena ${ }^{1}$, K.S. Kadian ${ }^{2}$, B.S. Meena ${ }^{3}$, Gunjan Bhandari ${ }^{4}$ and Vikash Kumar ${ }^{5}$ \\ 1,2 \&3. Principal Scientist, 4\&5. Ph. D. Scholar, ICAR- National Dairy Research Institute, Karnal, Haryana \\ Corresponding author e-mail :drhrms@gmail.com \\ Paper Received on September 14, 2021, Accepted on November 28, 2021 and Published Online on January 01,2022
}

\begin{abstract}
This study was undertaken to get a comprehensive idea about the favourable and unfavourable factors for adoption of dairy automation/machinations as perceived by dairy farmers, and study the economic impact of semi-automatic milking machine for small, medium and large dairy unit using the analysis of total cost and monetary benefits. The study was carried out in north Indian states, 30 commercial dairy farmers were selected constituting a total of 150 respondents practicing commercial dairy farming under survey method of investigation. Results revealed that time saving in dairy farm operations, drudgery reduction, and maintenance of hygiene and quality of milk and milk products were perceived as top three favourable factors for adoption of dairy automation or machination. The high initial investment required for dairy automation, no extra milk price for hygiene and quality products through the adoption of dairy automation in the market, and high cost of equipment and less subsidy provided by the government were perceived as top three favourable factors for adoption of dairy automation or machination. The study indicated that adoption score of the respondents were not significantly correlated with age. It implies that age, education, family size land holding and experiences of dairy farming does not affect the adoption of dairy automation technologies. The additional monetary benefits apart from this economic benefit's other benefits such as clean and hygiene milk, health care and management in economic terms were calculated about 43800, 39,600, and 64,000 per year for small, medium, and large dairy unit, respectively.
\end{abstract}

Key words: Automation; Investment; Monetary benefits; Semi-automatic milking machine; survey.

The livestock farming has been witnessing agriculture Sector by increasing share in agricultural GDP. However, the prosperity of livestock sector is conditioned by mechanisation and support services (Chandel, 2014). Automation refers to the use of control systems and information technologies, and machines to optimize productivity at the dairy farm in milk production and prompt and efficient delivery of services (Kanjilal et al., 2014). Variation in temperatures affect the health of animals adversely and lowers the milk production. In order to overcome these adversities, initiatives have been designed to escape these kinds of sensitive circumstances by using technology such as integrated, wireless sensor, and IOT (Goswami, 2021). In modernized dairy farming, automation has a great role; it has assisted the world over dairymen to integrate numerous new and innovative technologies to make the most of yield and profit in the farm (Jacobs and Siegford, 2012). Automation has high prospects for adding the value to agricultural and 
dairy products. Among one of these processes, the most popular includes automation guided milking of cows at the dairy farms through Automated Milking Systems. Limited work has been done to identify the positive and negative factors that influence the decision of farmers to go for adoption of automation in dairy farming at dairy farms (Bademosi and Issa, 2021). It also increases the profitability of automated dairy farms than conventionally managed dairies, when the scenario of rapidly increasing wage rates versus those of stable wage rates (Salfer et al., 2017). Previous studies suggest that there are limited understanding of how the potential innovations such as automation can be translated into widespread adoption in the dairy farming sector, which has been slow to date (Gargiulo et al., 2018). In order to reduce the uncertainty with emerging automated technologies at dairy farm, greater public and private research and development collaboration is required to foster knowledge development and exchange (Eastwood and Renwick, 2020).

By year 2015, there was up to 25,000 dairy farms adopting dairy automation technologies worldwide, with the technology found as most popular in countries namely, Netherlands and Scandinavia (Rodenberg, 2017). The benefit of automatic milking systems could be an increase in milk production as it normally allows cows to be milked three or more times each day. In comparison to milking strategy of obtaining milk twice a day milking strategy, it could also increase the milk production up to 12 per cent (Jacobs and Siegford, 2012). Factors for adoption of dairy automation/ machinations : In the atmosphere of globalization, it becomes necessary to produce higher quality products at efficient cost. This will only be possible by giving up old traditional production techniques and adopting new and modern ones. In line of which, the factors for adoption of dairy automation/machination have been discussed under two sub- heads namely, favourable factors for adoption of dairy automation/machinations, and unfavourable factors for the adoption of dairy automation technologies. The study has attempted to investigate the above two factors through primary (survey) data in regard to issues and prospects for adoption of automated milking system.

\section{METHODOLOGY}

The present study was conducted in north India.
North India consists of 7 states (ISCS), out of these 7 states, 5 states namely Haryana, Punjab, Delhi, Rajasthan, and Uttar Pradesh were selected for the study. From each state, one district was purposively selected based on the highest milk production in the states. Due to the unavailability of documented records of commercial dairy farmers, a snowball sampling technique was used to reach those progressive commercial dairy farmers. From each district, 30 commercial dairy farmers were selected constituting a total of 150 respondents practicing commercial dairy farming. Based on milking machine requirements, Dairy units were classified into 3 categories as Small dairy units (20-30 animals), Medium (30-60 animals), and large dairy unit (60-100 animals). The survey was conducted to explore the favourable and unfavourable factors for adoption of dairy automation/machinations as perceived by dairy farmers, and study the economic impact of semi-automatic milking machine for small, medium and large dairy unit using the analysis of total cost and monetary benefits.

\section{RESULTS AND DISCUSSION}

Favourable factors for adoption of dairy automation/machinations: The factors affecting the adoption of innovations play an important role in the activities aimed at improving the agricultural practices and as a result, the quality of life of the farmers. Certain qualifications on the part of the farmers facilitate the adoption of innovations which plays an important role in improving dairying in the region. These were important factors that motivate commercial dairy farmers for adoption of automation in their dairy farms. Various factors affecting the adoption of various equipment for dairy automation/ machinations were time-saving in dairy farm operations (as perceived by $86.00 \%$ of respondents. Ddrudgery reduction in dairy farm operations and maintains hygiene, and quality of milk and milk products were perceived by 75.53 and 67.33 per cent respondents respectively. It was found that 52.77 per cent respondents perceived the increase in cost of dairy farm production due to automation (Table 1). This finding was in consonance with the reporting of Tajeda et al. (2020) who revealed that high cost of investment was major limiting factor which hindered the farms to not go for automated milking system as perceived by 91.00 per cent of the respondents. The 
reliability of the automated milking system was also questioned by 56.00 per cent of the respondents. Time saving factor for due consideration to adopt automated milking system was recognised by 86.00 per cent respondents. This finding was supported by a study conducted by Hansen (2015) in Norway, who revealed that increased flexibility of time management, followed by workload savings was major factor affecting farmers to go for automated milking system. It was found that increase in number of dairy animals in the herd was perceived as favorable factor for adoption of dairy automation by 34.00 per cent respondents only (Table 1), similar to study conducted by Tajeda et al. (2020) in Idaho, where herd size was found non-significant in Probit model regarding assumption that that smaller herdsized dairies had more interest in installing AMS. About half of respondents recognised the reduced cost of dairy farm production due to adoption of automation as factor for adoption of dairy automation technologies. The labour cost shares major part in cost of operation of dairy farm. Thus, it can be inferred that the farmers recognized the cost of labour as replacement cost for automation. This finding was also supported by Bijl et al. (2017), who conducted a study in Netherlands and revealed that average of 29 per cent of lower labor was reduced due to adoption of automation at dairy farms. Other factors such as availability of credit facilities for the purchase of dairy equipment, increased labour productivity, reduced cost of dairy farm production and improved quality of life, and rural upliftment were the other main motivational factors for the adoption of dairy farm automation.

Unfavourable factors for the adoption of dairy automation technologies: Identifying the unfavourable

Table 1. Favourable factors for the adoption of dairy automation technologies

\begin{tabular}{lll}
\hline Factors & No. & $\%$ \\
\hline Time saving in dairy farm operations & 129 & 86.00 \\
Drudgery reduction & 113 & 75.33 \\
Maintain hygiene \& quality of milk \& product & 101 & 67.33 \\
Credit facilities for purchase of dairy equipment & 90 & 60.00 \\
Increased dairy farm productivity & 85 & 56.66 \\
Increased labour productivity & 82 & 54.66 \\
Reduced cost of dairy farm production & 71 & 47.33 \\
Commercialization and diversification of dairy farm & 58 & 38.33 \\
Increased dairy animal in the herd & 51 & 34.00 \\
Improved quality of life and rural upliftment & 127 & 84.66 \\
\hline
\end{tabular}

factors for the adoption of dairy automation technologies has always been facing scarce research attempts (Bademosi and Issa, 2021). Various factors associated with dairy farm technologies that hinder the adoption of these important technological tools has been presented in Table 2. It was found that 84.66 per cent respondents perceived high initial investment required for dairy automation as major unfavorable factor for the adoption of automation technologies. This finding was supported through a study conducted by Bademosi and Issa (2021) in United States, which revealed that adoption of automation at dairy farms was adversely affected mainly by the initial investment costs. No extra milk price for hygiene and quality products through the adoption of dairy automation in the market was recognized as limiting factor for adoption of automation by 74.33 per cent of respondents. A study conducted by Tomy and Pardede (2018) also highlighted those factors associated with knowledge of consumer acceptance of the technology, and potential market size affect the choice of decision maker to adopt the innovation. High cost of equipment, and less subsidy provided by the government was third top unfavorable factors were reported by 67.33 per cent. Other hindering factors such as high repair and maintenance charges of equipment was perceived as an add to list of factors by 60.00 per cent of respondents, this finding was supported by Groover (2020), who revealed that higher level of maintenance needed for automated machine as compared to conventional ones, accompanied with a lower degree of flexibility in terms of the possible products as compared with a manual system. Non availability of skilled labour for dairy automation, highinterest rates on loans and GST for purchase of dairy equipment, and lack of custom hiring centre for dairy equipment were those factors which were less recognised by farmers as unfavourable factors for the adoption of automation technologies. Thus, we can infer that uncertainty around the characteristics of an innovation (such as automation at dairy farm), infrastructural implications on farm, the level of adaptation required by farmers, and the impact on future options are all aspects of technological uncertainty (Klerkx et al., 2010; Tomy and Pardede, 2018). A study conducted by Singh et al. (2010) in Haryana also revealed that nearly 70.00 per cent of farmers had medium level of overall adoption of scientific dairy farming practices. 
Table 2. Unfavourable factors for the adoption of automation technologies

\begin{tabular}{lll}
\hline Factors & No. & \% \\
\hline $\begin{array}{l}\text { The high initial investment required for } \\
\text { dairy automation }\end{array}$ & 127 & 84.66 \\
$\begin{array}{l}\text { No extra milk price for hygiene and quality } \\
\text { products through the adoption of dairy }\end{array}$ & 113 & 75.33 \\
$\begin{array}{l}\text { automation in the market } \\
\text { High cost of equipment and less subsidy }\end{array}$ & 101 & 67.33 \\
$\begin{array}{l}\text { provided by the government } \\
\text { High repair and maintenance of equipment }\end{array}$ & 90 & 60.00 \\
$\begin{array}{l}\text { Inadequacy of services- centres for proper } \\
\text { maintenance }\end{array}$ & 85 & 56.66 \\
$\begin{array}{l}\text { Low cost of milk in the market } \\
\begin{array}{l}\text { Very high cost of IT support and sensors } \\
\text { for dairy farm }\end{array}\end{array}$ & 71 & 47.33 \\
$\begin{array}{l}\text { Non availability of skilled labour for dairy } \\
\text { automation }\end{array}$ & 58 & 38.33 \\
$\begin{array}{l}\text { High-interest rates on loans and GST for } \\
\text { purchase of dairy equipment }\end{array}$ & 54 & 36.00 \\
\begin{tabular}{l} 
Lack of custom hiring center for dairy equipment \\
\hline
\end{tabular} & 51 & 34.00 \\
\hline
\end{tabular}

Table 3. Relationship between socio-economic factors and adoption of dairy automation technologies

\begin{tabular}{ll}
\hline Factors & "r" \\
\hline Age & 0.083 \\
Education & 0.171 \\
Family size & 0.060 \\
Land Holding & 0.114 \\
Experience of dairy farming & 0.234 \\
Herd size & $0.307^{* *}$ \\
Average Peak yield of animals & $0.262^{* *}$ \\
Milk production of farm & $0.239^{*}$ \\
Milk sale & $0.227^{*}$ \\
Annual Income & $0.281^{* *}$ \\
Risk orientation & $0.214^{*}$ \\
Social media & $0.320^{*}$ \\
\hline
\end{tabular}

**Correlation significant at 0.01 level (2-tailed)

*Correlation significant at 0.05 level (2-tailed)

Relationship of selected independent variables with the adoption of dairy automation: The relationship of various independent variables with the adoption of dairy automation technologies have been presented in Table 3. Adoption score of the respondents were not significantly correlated with age. It implies that age, education, family size land holding and experiences of dairy farming does not affect the adoption of dairy automation technologies. The respondents' adoption scores were significantly correlated with Herd size, average peak yield of animal and annual income at 5 per cent level of significance $(\mathrm{P}<0.05)$. Whereas as variables such as milk production of farm, milk sale, risk orientation and social media at 1 per cent level of significance $(\mathrm{P}<0.01)$ were found to have a significant relationship. It implies that if the respondent is exposed to more mass media and has more milk production and sale farmers adopted the dairy farm automation technologies.

Economic impact of the commonly adopted dairy farm equipment : The economic impact of commonly adopted dairy farm equipment was calculated with and without approach. Based on milking machine requirements, Dairy units were classified into 3 categories as Small dairy units (20-30 animals), Medium (30-60 animals), and large dairy unit (60-100 animals). According to respondents (who adopted milking machine) and experts in the field, for a small dairy unit one unit of two bucket milking machine is sufficient, two units of two bucket milking machine required for medium unit and in case of large dairy unit one unit of six buckets milking machine is required for satisfactory milking of large dairy unit which have dairy animal up to 100 . The study indicated that Milking Machine was found to be the most commonly adopted $(42.00 \%)$ dairy automation equipment in the study area. In the light of the objective economic impact of the adoption of milking machine was calculated. A relatively little reduction in the initial cost of automation at dairy farm, an increase in the economic life of the equipment, or a large increase in the value of milking labor increased the economic return of automation on dairy farm relative to conventional milking systems over the all size of farm (Rotz et al., 2002).

Economic impact of semi-automatic milking machine for small dairy unit : For a small dairy of 20 to 30 milch animals, Total investment for the adoption of milking machine was calculated 52200 in a year and this is the cost of milking machine plus operational cost like depreciation on the milking machine, repair and maintained cost, and electricity cost (Table 3 ). In the adoption of one unit of two bucket milking machine, an average amount of 96000/ year can be saved on the labour cost required for milking. The additional monetary benefits were calculated about 43800 per year, apart from this economic benefit's other benefits such as clean 
and hygiene milk, health care of animals, better management of animals, and early detection of animal diseases were can not be calculated in economic terms. Thus, it can be concluded that a farmer can get back the money invested in a semi-automatic milking machine within one year.

Table 4. Economic impact of milking machine for small dairy unit (20-30 Milch Animals)

\begin{tabular}{lr}
\hline Particulars & Amount (/Year) \\
\hline A.Cost of two bucket milking machine & 40000.00 \\
Depreciation on milking machine@10\% & 3500.00 \\
Repair and maintenance charges & 1500.00 \\
Electricity charges & 7200.00 \\
B.Additional cost & 12200.00 \\
C. Total cost & 52200.00 \\
D. Saving of labour cost @8000/Month & 96000.00 \\
required for milking & \\
E. Additional Monetary Benefits (C-D) & 43800.00 \\
\hline
\end{tabular}

Table 5. Economic impact of semi- automatic milking machine for medium dairy unit

\begin{tabular}{lr}
\hline Particulars & Amount (/Year) \\
\hline A. Cost of 2 unit of two bucket milking machine & $80,000.00$ \\
Depreciation on milking machine@10\% & $7,000.00$ \\
Repair and maintenance charges & $3,000.00$ \\
Electricity charges & $14,400.00$ \\
B. Additional cost & $24,400.00$ \\
C. Total cost(A+B) & $1,04,400.00$ \\
D. Saving of labour cost @ $8000 /$ Month & 144000.00 \\
required for milking & \\
E. Additional Monetary Benefits (C-D) & 39600.00 \\
\hline
\end{tabular}

Economic impact of semi-automatic milking machine for medium dairy unit : For a medium dairy unit of 30 to 50 milch animals, the additional returns due to the adoption of two units of two bucket semi-automatic milking machine were found to be 39600/ year due to a reduction in the labour cost required for milking (Table 4). For a Medium dairy of 30 to 50 milch animals, an average amount of 1,44000 / year can be saved on the labour cost required for milking. The additional cost incurred due to the adoption of two unit of two bucks semi-automatic milking machine included depreciation charges, repair \& maintenance charges, and electricity charges which were found to be 24400 / year. Additional monetary benefits due to the adoption of two units of semi-automatic milking machine 39600/ year. Thus, it can be concluded adoption of a milking machine was found to be beneficial for a farmer having a herd size of 30 to 50 animals to purchase two units of semi-automatic milking machine as the cost spent on the machine can be recovered by the farmer within one year. Thus, it can be concluded it will be beneficial for a farmer having a herd size of 30 to 50 animals to purchase two units of semiautomatic milking machine as the cost spent on the machine can be recovered by the farmer within two years.

Economic impact of semi-automatic milking machine for large dairy unit : For a large dairy of 60 to 100 milch animals, the Total investment for the adoption of milking machine was calculated 224000 in a year and this is the cost of milking machine plus operational cost like depreciation on the milking machine, repair and maintained cost, and electricity cost (Table 5). In the adoption of one unit of two bucket milking machine, an average amount of 288000/ year can be saved on the labour cost required for milking. The additional monetary benefits were calculated about 64000 per year, apart from this economic benefit's other benefits such as clean and hygiene milk, health care of animals, better management of animals, and early detection of animal diseases were can not be calculated in economic terms. Thus, it can be concluded that a farmer can get back the money invested on a semi-automatic milking machine within one year. We can see that the ratio of total cost and additional monetary benefits was not so well established on yearly basis due to the probable reason that over the long-term, the adoption of automatic milking provided a small gain in annual net return at initial period of establishment (Rotz et al., 2002).

Table 5. Economic impact of semi-automatic milking machine for medium dairy unit

Particulars Amount (/Year)

A. Cost of 1 unit of six bucket milking machine $\quad 1,80,000.00$

Depreciation on milking machine@10\% $\quad 18,000.00$

Repair and maintenance charges $\quad 9,000.00$

Electricity charges $\quad 17,000.00$

B. Additional cost $\quad 44,000.00$

C. Total cost $(\mathrm{A}+\mathrm{B}) \quad 2,24000.00$

D. Saving of labour cost @8000/Month $\quad 288000.00$ required for milking

Additional Monetary Benefits (C-D) $\quad 64000.00$

\section{CONCLUSION}

Identifying the positive and negative factors influencing the decision of farmers towards adoption of 
automation in dairy farming at dairy farms, and studying its economic impact for dairy farmers having various size of dairy unit could be imperative to gain imperative insight towards the innovation driven dairy farming. The time saving operations, drudgery reduction, and maintenance of hygiene and quality of milk and milk products were major favourable factors for adoption of dairy automation or machination. The high initial investment automation, and lack of remunerative milk price for quality products through the adoption of dairy automation in the market were among major unfavourable factors for adoption of dairy automation or machination. Thus, increased flexibility of time management, and workload savings could be major observable attributes for farmers to go for automated milking system. The additional monetary benefits in economic terms were calculated about 43800, 39,600, and 64,000 per year for small, medium, and large dairy unit, respectively. Suitable interventions and awareness about subsidy should be encouraged among dairy farms to boom the scenario of dairy farming by availing the benefits of mechanisation (Rptz et al., 2002).

\section{CONFLICTS OF INTEREST}

The authors declare that they have no conflicts of interest.

\section{REFERENCES}

Bademosi, F. and Issa, R.R. (2021). Factors influencing adoption and integration of construction robotics and automation technology in the US. J. of Construction Engg. and Management, 147 (8) : 04021075.

Bijl, R.; Kooistra, S. R. and Hogeveen, H. (2007). The profitability of automatic milking on Dutch dairy farms. J. of Dairy Sci., $90(1), 239-248$.

Chandel, B. S. (2014). Effectiveness of artificial insemination in dairy cattles: recent evidences from India's milking state of Gujarat. Indian Res.J.Ext. Edu., 14(4): 18-26.

Eastwood, C. R. and Renwick, A. (2020). Innovation uncertainty impacts the adoption of smarter farming approaches. Frontiers in Sustainable Food Systems, 4.

Gargiulo, J. I.; Eastwood, C. R.; Garcia, S. C. and Lyons, N. A. (2018). Dairy farmers with larger herd sizes adopt more precision dairy technologies. J. of Dairy Sci., 101(6): 5466-5473.

Goswami, S. (2021). Implementation of automatic cooling system for cattle shed and its effect on milk production. Indian Res.J.Ext. Edu., 21(2):137-141.

Groover, Mikell P. (2020). Automation. Encyclopedia Britannica, 22 Oct. 2020, https://www.britannica.com/technology/ automation. Accessed 31 May 2021.

Hansen, B. G. (2015). Robotic milking-farmer experiences and adoption rate in Jæren, Norway. J.of Rural Studies, 41: $109-117$.

Jacobs, J. A. and Siegford, J. M. (2012). Invited review: The impact of automatic milking systems on dairy cow management, behavior, health, and welfare. J. Dairy Sci., 95 (5): 22272247

Kanjilal, D.; Singh, D.; Reddy, R. and Mathew, J. (2014). Smart farm: extending automation to the farm level. Int. J. Sci. Tech. Res, 3 (7):109-113.

Klerkx, L.; Aarts, N. and Leeuwis, C. (2010). Adaptive management in agricultural innovation systems: The interactions between innovation networks and their environment. Agril.systems, 103(6): 390-400.

Rodenburg, J. (2017). Robotic milking : Technology, farm design, and effects on work flow. J. of dairy Sci., 100 (9): $7729-7738$.

Rotz, C. A.; Coiner, C. U. and Soder, K. J. (2002). Economic impact of automatic milking systems on dairy farms. In 2002 ASAE Annual Meeting (p. 1).

Salfer, J. A.; Endres, M. I.; Lazarus, W. and Minegishi, K. (2016). Finances and returns for robotic dairies. J. of Animal Sci., 94 $: 17-17$.

Singh, S.; Kumar, R. and Meena, B. S. (2016). Adoption level of scientific dairy farming practices by dairy farmers of Haryana. Indian Res.J.Ext. Edu., 10(3) : 45-48.

Tomy, S. and Pardede, E. (2018). From uncertainties to successful start-ups: A data analytic approach to predict success in technological entrepreneurship. Sustainability, 10 (3): $602 .$. 